\title{
Políica de renda básica à luz do feminismo interseccional
}

\author{
Recebido: 6 de abril de 2020 • Aprovado: 2 de julho de 2020 \\ https://doi.org/10.22395/ojum.v20n4la8
}

Lorena Fonseca

Universidade Federal de Minas Gerais, Belo Horizonte, Brasil

lorena.fonseca@outlook.com

https://orcid.org/0000-0003-4031-7574

\section{RESUMO}

O presente trabalho apresenta a proposta de renda básica incondicional de Philippe Van Parijs, como um projeto de liberdade, contrapondo-a com o feminismo interseccional. O objetivo é analisar o impacto da política de renda básica para mulheres excluídas do feminismo hegemônico. Propõe-se, assim, ampliar o debate sobre renda básica incondicional para mulheres que vivenciam entraves à liberdade e à igualdade advindos da interseção entre gênero, raça e classe. A hipótese inicial desta pesquisa é que a teoria de Van Parijs conseguiria responder às objeções interseccionais que lhe são contrapostas. Por meio de uma revisão bibliográfica, a análise foi feita em termos de "opções e vida" e de "renda". Concluiu-se que a proposição vanparijsiana, embora possa ser um instrumento de liberdade necessário, não consegue atender a integralidade dos desafios apresentados pelo feminismo interseccional, o que refuta hipótese inicial deste trabalho.

Palavras-chave: renda básica; feminismo interseccional; interseccionalidade; liberdade; igualdade; renda. 


\section{La política de renta básica a la luz del feminismo interseccional}

\section{RESUMEN}

Este artículo presenta la propuesta de Philippe Van Parijs de una renta básica incondicional como proyecto de libertad, contrastándola con el feminismo interseccional. El objetivo es analizar el impacto de la política de renta básica para las mujeres excluidas del feminismo hegemónico. Así, se propone ampliar el debate sobre la renta básica incondicional para las mujeres que experimentan obstáculos a la libertad y la igualdad derivados de la intersección entre género, raza y clase. La hipótesis inicial de esta investigación es que la teoría de Van Parijs podría responder a las objeciones interseccionales que se le oponen. A través de una revisión bibliográfica, el análisis se realizó en términos de "opciones y vida" e "ingresos". Se llegó a la conclusión de que la proposición vanparijsiana, aunque puede ser un instrumento necesario de la libertad, no puede hacer frente a la totalidad de los desafíos que presenta el feminismo interseccional, lo que refuta la hipótesis inicial de este trabajo.

Palabras clave: renta básica; feminismo interseccional; interseccionalidad; libertad; igualdad; ingresos.

\section{Basic Income Policy in the Light of Intersectional Feminism ABSTRACT}

This paper presents Philippe Van Parijs' proposal of unconditional basic income as a project of freedom, contrasting it with intersectional feminism. The aim is to analyze the impact of the basic income policy for women excluded from hegemonic feminism. It thus proposes to broaden the debate on unconditional basic income for women who experience barriers to freedom and equality arising from the intersection of gender, race, and class. The initial hypothesis of this research is that Van Parijs's theory would be able to respond to the intersectional objections against it. Through a literature review, the analysis was done in terms of "choices and life" and "income". It was concluded that the vanparijsian proposition, while it may be a necessary instrument of freedom, fails to meet the entirety of the challenges presented by intersectional feminism, which refutes the initial hypothesis of this paper.

Keywords: basic income; intersectional feminism; intersectionality; freedom; equality; income. 


\section{INTRODUÇÃO}

O presente trabalho faz parte de pesquisa desenvolvida no âmbito do mestrado da Faculdade de Direito da Universidade Federal de Minas Gerais, Brasil, realizada com o apoio da Coordenação de Aperfeiçoamento de Pessoal de Nível Superior.

Este trabalho tem o condão de apresentar a política de renda básica de Philippe Van Parijs, como um projeto de liberdade, contrapondo-a com o feminismo interseccional. O objetivo é analisar o impacto da renda básica para as mulheres excluídas do feminismo hegemônico.

A opção pela agenda acadêmica feminista, a partir da interseccionalidade, contribui para a discussão da renda básica incondicional por auxiliar no exame da discriminação estrutural baseada — não apenas no gênero, mas também nas discriminações provenientes da raça e da classe que tornam algumas mulheres mais vulneráveis à pobreza e a várias privações de liberdade.

Esta pesquisa tem abordagem qualitativa, ou seja, não enfoca representatividades numéricas ou testes de correlações sociais, mas sim o aprofundamento da compreensão sobre um determinado problema e a explicação da dinâmica lógica das relações sociais. Trata-se de uma pesquisa de natureza básica, uma vez que objetiva gerar conhecimentos que envolvam interesses universais. Quanto ao procedimento, o trabalho faz uma revisão de bibliografia, pois recolhe informações e conhecimentos prévios a respeito do problema de pesquisa (Silveira e Córdova, 2009).

O trabalho está organizado da seguinte maneira: em primeiro lugar, busca-se compreender a natureza da liberdade real para Philippe Van Parijs, bem como sua proposta de renda básica incondicional e universal. Em segundo lugar, esclarecem-se as definições de interseccionalidade e a importância de adicioná-las na discussão da renda básica. Por fim, é feito um diálogo da política de renda básica de Van Parijs com elementos do feminismo interseccional.

\section{LIBERDADE REAL E RENDA BÁSICA INCONDICIONAL — A PROPOSTA DE PHILIPPE VAN PARIJS}

Philippe Van Parijs defende a implementação de uma renda básica incondicional e universal como expressão de justiça, destacando-se como um dos grandes filósofos políticos da contemporaneidade (Hunyadi e Mänz, 1998; Birnbaum, 2012). Nas primeiras frases de sua obra Real freedom for all: What (if anything) can justify capitalism?, Van Parijs (1995) afirma que "nossas sociedades capitalistas estão repletas de desigualdades inaceitáveis" e que "a liberdade é de suma importância (p. 1)".' O autor explica que o livro foi escrito "por alguém que defende fortemente essas duas convicções"2 e

[No original] "One: Our capitalist societies are replete with unacceptable inequalities. Two: Freedom is of paramount importance".

2 [No original] "This book is written by someone who strongly holds these two convictions". 
é dirigido principalmente àqueles que compartilham dessas convicções com ele (Van Parijs, 1995, p. 1).

Com essa declaração introdutória, Van Parijs (1995) busca conciliar liberdade com igualdade em sua teoria, e o uso da palavra "convicções" expressa a importância de ambas na obra (Hunyadi e Mänz, 1998). O autor argumenta negativamente em cada passo de sua construção teórica, no sentido de confrontar concepções existentes de liberdade, deixando sua própria concepção se destacar por causa de sua preeminência, em vez de argumentar por dedução de premissas explícitas (Hunyadi e Mänz, 1998).

Visando justificar a renda básica, Van Parijs (1995) delineou uma concepção de liberdade que pode ser construída em três passos. Primeiro: clarifica as dimensões de liberdade. Segundo: indica que liberdade deve estar ligada a alguma noção de desejo potencial. Terceiro: explica que, para que a liberdade sirva como justificativa para a renda básica, deve-se pensar nas condições reais de sua aplicação.

O primeiro passo da construção do argumento de Van Parijs (1995) refere-se à definição da liberdade. O autor afirma que sua concepção ideal teria "uma sociedade de indivíduos livres, para a qual a liberdade da sociedade não é mais do que um meio" (p. 17). ${ }^{3}$ Uma sociedade livre seria "uma sociedade cujos membros são todos realmente livres — ou melhor, tão livres quanto possível" (p. 25). ${ }^{4}$

No primeiro passo da construção do argumento, Van Parijs (1995) contrapõe liberdade positiva e liberdade negativa. Para o autor, a liberdade positiva refere-se à autonomia de um indivíduo. É a liberdade de fazer certas coisas - a autorrealização individual. Na liberdade positiva, ou seja, na "liberdade para", o grau de liberdade é definido pela capacidade de fazer o que se "deseja autonomamente" (Elster, 1983, p. 128).

Já a liberdade negativa é concebida como liberdade de coerção, a "liberdade de". O conceito de liberdade negativa está preocupado com as "restrições de origem humana, com fronteiras, regras e leis que estabelecem os limites da liberdade", determinando, portanto, o espaço de liberdade de cada indivíduo (Berlin, 1969, p. 122). A liberdade negativa envolve a reivindicação de menos limites, ao mesmo tempo que aceita um estado mínimo em troca de segurança - o que envolve especialmente uma manutenção da lei e dos direitos de propriedade (Sommer, 2016).

Por isso, Van Parijs (1995) argumenta que a concepção negativa de liberdade atribui a todos uma esfera de soberania individual na qual ninguém pode interferir. E é precisamente por causa dessa não interferência, ou seja, por não estar "sendo

3 [No original] "The ideal, however, remains a society of free individuals, to which the freedom of society is no more than a means".

4 [No original] "What is, then, a free society? It is a society whose members are all really free - or rather, as really free as possible". 
impedida", essa liberdade pode ser chamada de negativa (Van Parijs, 1995). A propriedade de si, componente da liberdade real de Van Parijs, impõe limitações sobre concepções aceitáveis de liberdade: qualquer que seja a definição de liberdade, ela terá que respeitar a propriedade de si mesmo (Van Parijs, 1995).

Definidas as dimensões de liberdade, o segundo passo da construção do argumento de Van Parijs trata da objeção do "escravo satisfeito" ("contented slave") e da noção de desejo potencial ("potential desire") (Van Parijs, 1995, p. 18). Nesse estágio, o autor usa uma noção de desejo potencial para definir liberdade. Quando a liberdade é definida pela individualidade soberana de "liberdade de" ("freedom from"), ela deve incluir dois elementos distintos: primeiro, a emancipação de certos constrangimentos; segundo, o projeto de ter um plano a realizar — porque só pode haver restrições na realização de algum tipo de projeto (Van Parijs, 1995).

Isso aponta uma inadequação da distinção clássica entre liberdade negativa ("liberdade de") e liberdade positiva ("liberdade para"). Van Parijs (1995) explica que há enorme confusão no contraste entre liberdade negativa e liberdade positiva, na medida em que estar livre "de" algum obstáculo, na presença do qual a liberdade desaparece, é sempre também a liberdade "para" exercer as atividades em causa. Dessa forma, liberdade negativa inclui algum tipo de momento positivo, ou seja, não há liberdade negativa sem a positiva (Van Parijs, 1995, p. 18).

Nessa monta, a liberdade parece estar naturalmente ligada ao desejo, e essa conexão se depara com uma objeção que subestima essa definição de liberdade. Van Parijs (1995, p. 18) chama essa objeção de "escravo satisfeito" ("contented-slave"), haja vista que, se a liberdade e o desejo estão conectados, é sempre possível manipular o desejo de aumentar a liberdade, ou seja, um escravo - não livre por definição poderia aumentar sua liberdade ajustando suas preferências à sua situação.

Hunyai e Manz (1998) explicam essa objeção apontada por Van Parijs com o seguinte exemplo: imagine um tirano que, com algum artifício de lavar o cérebro, aniquila todos os desejos de seus súditos para que se contentem com as situações que a eles são impostas. Na ausência do desejo por outra situação, ou por falta de referência sobre outras condições de vida possíveis, seus súditos se sentirão livres.

Assim, o problema da conexão entre as preferências individuais e o grau de liberdade é que a mudança nas preferências alteraria a liberdade experimentada. Pode até ser possível manipular o conjunto de preferências para aumentar a liberdade (Sommer, 2016). Se alguém não quiser algo que esteja fora do alcance de qualquer maneira, o indivíduo não sofrerá com essa restrição. A manipulação de preferências é possível tanto do lado de fora quanto do lado de dentro. Se alguém dissuadir da vida normal, reduzindo seus próprios desejos, ela aumentaria sua liberdade de acordo com a definição (Sommer, 2016). 
Por isso, a resposta a esse problema não consiste necessariamente em separar a liberdade do desejo, mas separar liberdade do desejo factual. A noção de desejo potencial ("potential desire") implica não o que "queremos fazer" ("want to do"), mas o que "poderíamos querer fazer" ("might want to do") (Van Parijs, 1995, p. 19). Ao propor essa separação, ao mesmo tempo, respeita-se a definição de liberdade como soberania individual e responde-se ao problema do "escravo satisfeito".

A liberdade, nesse sentido, pode então ser definida pelo fato de não ser impedido do que poderíamos querer fazer. Dito em outras palavras, a separação entre liberdade e desejo real pode operar graças à noção contrafactual de desejo potencial. O desejo potencial não é contrafactual por causa dos desejos que realmente temos — os quais estão sujeitos à manipulação, mas por causa dos desejos que podemos querer ter - $\mathrm{O}$ que supostamente estão excluídos de tal manipulação (Sommer, 2016).

Superada a objeção do "escravo satisfeito" com a noção de "desejo potencial", a terceira etapa do argumento de Van Parijs consiste em estabelecer as condições do exercício dessa liberdade. Se liberdade é definida como desejo potencial, devemos estabelecer o que pode, nessa visão, constituir um obstáculo que impede de se fazer o que se poderia querer fazer. Só quando estabelecidos os obstáculos a essa liberdade concebida, é que se pode pensar nas medidas susceptíveis de aboli-los para que se exerça realmente a liberdade.

Para os defensores de uma noção exclusiva de liberdade negativa, como Hayek (1960) ou Buchanan (1975), apenas a coerção pode contar como um obstáculo limitador da liberdade. Para essa corrente, há liberdade sempre que ninguém exerce coerção sobre as opções que se tenha direito de escolher. Nessa concepção de liberdade, separa-se estritamente a liberdade do desejo, o que implica a seguinte consequência indesejável: suponha que alguém seja tão pobre que não possa proporcionar uma vida decente para si e sua família. Esse indivíduo só tem a opção de aceitar um trabalho ruim que ele não quer. Na visão dos defensores da liberdade negativa pura, esse indivíduo é perfeitamente livre, uma vez que não foi coagido em seu conjunto de escolhas, e ninguém o forçou a aceitar o trabalho.

A problemática existente nessa vertente é o acesso a recursos. Apesar da falta de recursos, considera-se o sujeito livre porque as opções são respeitadas — ainda que limitadas. Para Van Parijs (1995), isso implica uma consequência contra intuitiva que mostra uma confusão entre possibilidade e capacidade. $O$ autor explica que se, por exemplo, um indivíduo não tem dinheiro, não estará realmente livre para participar de um cruzeiro, embora ninguém o proíba de fazê-lo. Ou seja, há possibilidade formal, mas não capacidade real de escolher outra coisa senão um péssimo trabalho.

Assim, se a definição de liberdade não leva em conta as capacidades, ela permanece puramente formal. É o acesso a recursos que dá oportunidades para realizar desejos, 
sendo parte integrante da definição de liberdade real. Se o desejo é definido como "desejo potencial", o exercício da liberdade real requer a possibilidade material (concebida em termos de acesso a esses recursos) de satisfazer, tanto quanto possível, não apenas o que o indivíduo quer fazer, mas o que ele pode querer fazer (Van Parijs, 1995).

Desse modo, Van Parijs (1995) justifica filosoficamente a instituição da renda básica, que se apresenta como uma quantia suficiente de dinheiro para permitir que se considerem o que se quer e o que se pode querer fazer. A renda básica surge para oferecer os meios, e não apenas o direito, de fazer o que se deseja. A política de renda básica incondicional e universal proposta por Van Parijs (1995) é crucialmente importante para garantir renda sem qualquer restrição à conduta da pessoa beneficiada; sem nenhuma restrição, especialmente, que derive do exercício ou não do trabalho pago.

Cada um dos seus membros da sociedade deve ter uma estrutura de direitos que dê segurança para o exercício da liberdade e propriedade de si e, além disso, é preciso que seja concedida a maior oportunidade possível para que cada pessoa faça qualquer coisa que queira fazer (Van Parijs, 1995). Nesse sentido, para Van Parijs, a renda básica incondicional seria a melhor maneira de garantir liberdade real para todos, pois seria uma base material firme para cada um desenvolver sua própria concepção de vida boa (Van Parijs, 1995).

A proposição de uma renda básica incondicional é vista por Van Parijs (1994) como uma política social que supera o estado de bem-estar social tradicional, pois trata-se de uma nova modalidade de intervenção estatal, assentada em outros padrões éticos que não aqueles que orientaram a implantação dos welfare states tradicionais.

Os tipos de welfare existentes, em geral, têm por base ora um modelo denominado de (1) bismarkiano, que consiste em um sistema de seguros sociais, de caráter obrigatório, que funciona ex-post; ora um de tipo (2) beveridgeano, que recorre à noção de solidariedade e assenta-se em transferências ex-ante e, por fim, (3) paineano, sustentado por uma concepção de equidade que se materializa na concessão de uma renda básica incondicional em determinada época (Diniz, 2007).

O modelo bismarkiano está fortemente ligado ao trabalho e à condição de assalariado. As contribuições obrigatórias sobre a remuneração dos trabalhadores permitem preservar tanto os trabalhadores quanto suas famílias de riscos como desemprego, doenças, velhice e falecimento. Já o modelo beveridgeano propicia seguridade social a quem não tem acesso a condição de trabalhador. É um mecanismo de renda em dinheiro garantido às famílias para atender as necessidades de subsistência. A concepção desse modelo está no princípio fundamental da assistência a quem está necessitado, por isso estão presentes as condicionalidades relacionadas à situação familiar como comprovação de renda e disposição para trabalhar. No modelo paineano, nenhuma dessas três condicionalidades está presente. Afasta-se da ideia da seguridade social 
e da assistência social, aproximando-se da justiça em conceder incondicionalmente uma dotação única a partir de certa idade (Vanderborght e Van Parijs, 2006).

A renda básica incondicional e universal proposta por Van Parijs (1995) difere das reformas das políticas sociais que introduziram formas de renda mínima, pagamentos de uma só vez ou de sistemas de seguridade social, na medida em que os beneficiários não precisam ter feito contribuições de seus ganhos passados para fazer jus ao benefício, ou mesmo ter idade específica. As formas de renda garantida condicionais são diferentes da política de renda básica incondicional por, pelo menos, quatro razões:

Primeiro, porque na renda garantida condicional é preciso fazer jus ao benefício. O beneficiário deve estar disposto a aceitar um emprego adequado ou um treinamento adequado, caso sejam oferecidos. Segundo, a pessoa precisa se submeter a uma verificação de meios, no sentido de que somente fará jus ao benefício caso existam boas razões para supor que ela não obtém uma renda suficiente de outras fontes. E terceiro, a obtenção do benefício, e de quanto ele será, depende de condições tais como com quem a pessoa vive, se vive por sua conta, ou com uma pessoa que tem emprego, ou com alguém desempregado, etc. E, por fim, a obtenção do benefício, e de quanto será, depende ainda de onde a pessoa vive, se vive, por exemplo, em uma área metropolitana, em uma cidade interiorana ou na zona rural. ${ }^{5}$ (Van Parijs, 1995, p. 34)

Essas propostas de renda garantida condicional são chamadas de "bônus estatal", de "dividendo nacional ou social", de "renda ou salário do cidadão", de "demogrant", de "renda básica", de "subsídio universal" etc. (Van Parijs, 1995, p. 34). No Brasil, por exemplo, o "Bolsa Família" é uma espécie desses tipos criados com objetivo de combater a pobreza e a miséria, através de um benefício monetário mensal condicionado à renda per capita, sendo exigidas contrapartidas referentes "ao exame pré-natal, ao acompanhamento nutricional, ao acompanhamento de saúde, à frequência escolar de 85 \% (oitenta e cinco por cento) em estabelecimento de ensino regular" (Lei n. 10.836, 2004).

Outro exemplo brasileiro, é o auxílio emergencial. Em 2020, durante o período de calamidade pública decorrente do novo coronavírus (covid-19), foi publicada a Lei 13.982/2020, que instituiu medidas excepcionais de proteção social aos trabalhadores. Entre as medidas adotadas por essa lei, está a concessão de auxílio emergencial no

5 [No original] "(1) To be entitled to the benefit, the beneficiary must, if she is not either working or unable to work, be willing to accept a suitable job, or to undergo suitable training, if offered. (2) She must pass a means test, in the sense that she is only entitled to the benefit if there are good grounds to believe that she has no access to a sufficient income from other sources. (3) Whether she is entitled to a benefit and how high the latter is depends on her household situation - for example, on whether she lives on her own, with a person who has a job, with a jobless person, etc. And finally (4) whether she is entitled to a benefit and how high the latter is depend on her place of residence, on whether she lives, for example, in a metropolitan area, in a provincial town, or in the country".

- O Bolsa Família não é objeto dessa pesquisa. Sobre a temática, ver Coêlho (2012) e (Rego e Pinzani (2013). 
valor de $\mathrm{R} \$ 600,00$ mensais, sob a condição de cumprimento de todos os requisitos estabelecidos. $^{7}$

Em contraste a essas propostas, a renda básica vanparijsiana é uma forma de renda mínima garantida tipicamente incondicional, em todos os aspectos mencionados anteriormente. A política de renda básica pensada por Van Parijs é paga a cada membro efetivo da sociedade, independentemente dos recursos dessa pessoa - se rica ou pobre, da disposição para trabalhar, do formato familiar ou de onde se vive. Portanto, é pago regularmente a todos na população, individualmente, e não como um único pagamento doméstico; é sem teste e não condicionado à situação familiar ou laboral.

A primeira condição - pago a cada membro da sociedade - é consequência da neutralidade em relação a diferentes planos de vida. A segunda condição independentemente dos recursos dessa pessoa, corresponde à alegação de Van Parijs de que tal transferência deve ser paga ex ante como uma renda básica incondicional e não como um imposto de renda negativo ex post. A terceira e a quarta condições, pago individualmente e sem teste, centram-se na transferência incondicional, ou seja, independentemente da situação do agregado familiar e dos arranjos de vida (Sommer, 2016).

Por isso, em resumo, a renda básica incondicional é diferente dos pagamentos padrão de política de bem-estar-social que, muitas vezes, estão subordinados à vontade de empreender, de emprego ou se relacionam com considerações locais, níveis de renda, posição dos parceiros ou de outras pessoas que vivem no lar. A renda básica incondicional é totalmente individualizada e, normalmente, não é reduzida quando as receitas de outras fontes são adicionadas (Van Parijs, 1995).

Além disso, devido à sua natureza incondicional, as pessoas podem contar, com segurança, com uma base material sobre a qual uma vida pode descansar firmemente, e qualquer outra renda, seja em dinheiro ou em espécie, do trabalho ou da poupança, do mercado ou do Estado, pode legitimamente ser adicionadas (Van Parijs, 1995). Em contrapartida, na definição de renda básica vanparijsiana, não há conexão com

7 Durante o período de 3 (três) meses, a contar da publicação da Lei 13.982/2020, seria concedido auxílio emergencial ao trabalhador que cumprisse cumulativamente os seguintes requisitos: I — seja maior de 18 (dezoito) anos de idade, salvo no caso de mães adolescentes; II — não tenha emprego formal ativo; III — não seja titular de benefício previdenciário ou assistencial ou beneficiário do seguro-desemprego ou de programa de transferência de renda federal, ressalvado, nos termos dos $\oint \oint 1^{\circ}$ e $2^{\circ}$, o Bolsa Família; IV - cuja renda familiar mensal per capita seja de até 1/2 (meio) salário-mínimo ou a renda familiar mensal total seja de até 3 (três) salários mínimos; V — que, no ano de 2018, não tenha recebido rendimentos tributáveis acima de $\mathbf{R} \$ 28.559,70$ (vinte e oito mil, quinhentos e cinquenta e nove reais e setenta centavos); e VI — que exerça atividade na condição de: a) microempreendedor individual (MEI); b) contribuinte individual do Regime Geral de Previdência Social que contribua na forma do caput ou do inciso I do $\S 2^{\circ}$ do art. 21 da Lei n. ${ }^{\circ} 8.212$, de 24 de julho de 1991; ou c) trabalhador informal, seja empregado, autônomo ou desempregado, de qualquer natureza, inclusive o intermitente inativo, inscrito no Cadastro Único para Programas Sociais do Governo Federal (CadÚnico) até 20 de março de 2020, ou que, nos termos de autodeclaração, cumpra o requisito do inciso IV. 
noções de necessidades básicas, ou seja, essa renda básica pode ficar aquém do que é considerado "necessário para uma existência decente" (Van Parijs, 1994, p. 77).

Além das quatro incondicionalidades da renda básica descritas acima para "leximinizar" a liberdade real para todos, há outras exigências às quais essa maximização deve estar sujeita. A implementação da política de renda básica vanparijsiana depende de duas condições: a primeira é a diversidade não dominada e a segunda é a sustentabilidade econômica.

Antes de explicarmos a primeira condição, a diversidade não dominada (undominated diversity), ${ }^{8}$ é preciso entender que a liberdade de Van Parijs é a "liberdade real" baseada na autonomia individual que permite que os indivíduos busquem sua própria concepção de vida boa. A preocupação de maximizar a liberdade real se concentra na dotação de meios que são a base dessa liberdade; assim, a alocação de recursos entre as pessoas é de grande importância, porque aumenta o conjunto de oportunidades de cada indivíduo (White, 1997). Nesse sentido, a abordagem de Van Parijs busca enfrentar as dificuldades e a heterogeneidade do mundo real, procurando, assim, encontrar uma maneira de lidar com o desafio de diferentes condições iniciais de vida, ou seja, lidar com diferentes preferências e diferentes dotações. O que está em questão, portanto, é quando a compensação é necessária e justificada em uma sociedade heterogênea (Sommer, 2016).

Dito em outras palavras, suponhamos que todos os indivíduos (inicialmente) recebam partes igualmente valiosas de recursos externos. Ainda assim, em tal situação, algumas pessoas seriam incapacitadas, enquanto outras não; algumas têm habilidades de mercado brilhantes, enquanto outras dificilmente têm talentos lucrativos; algumas são bonitas e engraçadas, outras não, e assim por diante. Por causa de tais diferenças nas dotações internas, os meios disponíveis às pessoas para fazer o que quiserem são desiguais e podem dar origem a reivindicações concorrentes por vários tipos de redistribuição contínua ou compensação única daqueles que são mais favoravelmente dotados (Birnbaum, 2004).

Sommer (2016) explica que, para Van Parijs, ser consistente com a teoria da "liberdade real" deve haver algum tipo de pagamento compensatório para equalizar as condições iniciais, porque, sem essas transferências, uma renda básica não ajudaria a aumentar a liberdade real de acordo com a chamada "oportunidade leximin". Por isso, do ponto de vista igualitário, a compensação é necessária para equalizar os fatores que estão além do controle do indivíduo, ou seja, aquelas questões de sorte. A maneira de lidar com essas questões, respeitando a neutralidade liberal, é alcançar a diversidade não dominada. Na teoria de Van Parijs, esse critério operaria no contexto da mais alta renda básica sustentável, conforme justificado pelo princípio da igualdade das dotações externas.

Este conceito foi apresentado pela primeira vez por Ackerman (1980). 
Van Parijs (1995, p. 75) propõe, assim, que a classe de pessoas cujas carências de ativos desse direito à compensação sejam determinadas como "diversidade dominada". Desse modo, os indivíduos devem ser compensados por deficits na dotação pessoal até que uma condição designada "diversidade não dominada" seja alcançada. "As dotações internas de 'A' (um vetor de talentos) dominam as dotações internas de 'B' se, e somente se, cada pessoa (dada sua própria concepção de vida boa) preferiria ter a primeira do que a segunda" (Van Parijs, 1995, p. 73). ${ }^{9}$ Dito de outro modo, a condição da diversidade não dominada exige que nenhum dom abrangente do indivíduo, compreendendo seus recursos internos e externos, seja dominado, no sentido de que existe algum outro indivíduo cuja dotação é unanimemente preferida à dele. Essa é a primeira exigência a qual a maximização da política de renda básica deve estar sujeita.

Ao tratar da diversidade dominada, abandona-se a suposição de que as capacidades das pessoas, ou seus recursos internos, são idênticos, pois "a despeito de terem rendas básicas idênticas, duas pessoas podem ter complexos de oportunidades muito diversos" (Van Parijs, 1994, p. 80). Por consequência, essas pessoas terão níveis diferentes de liberdade real, "se uma delas pode física e mentalmente fazer tudo o que a outra faz e muito mais" (Van Parijs, 1994, p. 80). Por essa razão, em geral, a liberdade real não será leximizada se tudo o que se faz é conceder a todos uma renda básica no mais elevado nível possível. A melhor forma de lidar com essa importante complicação consiste, portanto, na imposição da exigência de diversidade não dominada (Van Parijs, 1994).

Como a propriedade de si proíbe a compensação por meio da redistribuição de recursos internos, a diversidade não dominada deve ser perseguida, quando necessário, redistribuindo os ativos externos até que nenhum indivíduo permaneça dominado. A realização das compensações exigidas pela diversidade dominada tem uma prioridade importante, embora não absoluta, na determinação de como a receita fiscal deve ser redistribuída, o que constitui importante limite moral para a provisão da renda básica (Van Parijs, 1995).

A segunda exigência introduzida por Van Parijs (1995) é a sustentabilidade econômica. O autor aponta que, conforme a regra leximin, a renda básica deve ser a mais alta sustentável ("the highest sustainable"); entretanto, deve ter um nível que seja sustentável de um ano ao outro e de uma geração à outra. Por isso, deve-se escolher o tipo de taxação que pode gerar de forma durável a arrecadação mais elevada, e o índice dessa taxação deve ser levado a um nível correspondente ao pico da "Curva de Laffer". ${ }^{10}$ Ou seja, a taxação associada à maior arrecadação deve ser gerada de forma

9 [No original] "'A's internal endowments (a vector of talents) dominates B's internal endowments if and only if every person (given her own conception of the good life) would prefer to have the former than the latter".

10 De maneira sintética, a "Curva de Laffer" é uma teoria econômica que compara a porcentagem dos impostos cobrados com a quantidade que o governo pode obter como receita pública. Essa ideia foi 
durável, tendo em mente que parte dessa arrecadação será empregada para cuidar da liberdade e da diversidade dominada (Van Parijs, 1995).

Além disso, é importante o nível per capita de renda básica, o qual não é afetado somente pela arrecadação total, mas também pelo número de pessoas que existem. Por isso, Van Parijs (1995) explica que é preciso levar em conta os efeitos demográficos. Se um incremento da renda básica leva a uma expansão da população, a arrecadação máxima de impostos sustentável só poderá assegurar uma renda básica declinante.

Pode-se observar, portanto, que, na política de renda básica de Van Parijs, o tamanho do conjunto de oportunidades está diretamente ligado à renda, de modo que a distribuição regular assume papel central para o autor. Apoiado na liberdade real para todos, o autor buscou justificar normativamente a introdução de uma renda básica incondicional, paga a cada membro efetivo da sociedade individualmente, sem teste, independentemente da situação familiar ou laboral, da quantidade de recursos, da disposição para trabalhar ou do local onde se vive.

\section{FEMINISMO INTERSECCIONAL: DEFINIÇÕES E IMPORTÂNCIA}

Em termos gerais, a interseccionalidade se apresenta como um conceito-chave para compreender relações sociais de poder e contextos de desigualdade. Trata-se de um compromisso teórico-metodológico que busca capturar as consequências estruturais e dinâmicas da interação entre dois ou mais eixos de subordinação, dando visibilidade a desigualdades estruturadas pelo racismo, pelo patriarcalismo, pela opressão de classe e por outros sistemas discriminatórios (Crenshaw, 2002; Rodrigues, 2013; Magliano, 2015). Nesse sentido, a interseccionalidade:

Refere-se a uma teoria transdisciplinar voltada para a compreensão da complexidade das identidades e desigualdades sociais através de um enfoque integrado. Ela refuta o enclausuramento e a hierarquização dos grandes eixos da diferenciação social que são as categorias sexo/gênero, classe, raça, etnia, idade, deficiência e orientação sexual. A abordagem interseccional ultrapassa o simples reconhecimento da multiplicidade de sistemas de opressão que operam a partir dessas categorias e postula sua interação na produção e reprodução de desigualdades sociais." (Bilge, 2009, p. 70)

desenvolvida pelo economista Arthur Laffer, sendo defensor de que a diminuição dos impostos cobrados das empresas pode aumentar a arrecadação do Estado. A teoria explica que, a partir de um certo ponto, por mais que aumente a alíquota do imposto, este deverá gerar menos receita fiscal.

11 [No original] "L'intersectionnalité renvoie à une théorie transdisciplinaire visant à appréhender la complexité des identités et des inégalités sociales par une approche intégrée. Elle réfute le cloisonnement et la hiérarchisation des grands axes de la différenciation sociale que sont les catégories de sexe/genre, classe, race, ethnicité, âge, handicap et orientation sexuelle. L'approche intersectionnelle va audelà d'une simple reconnaissance de la multiplicité des systèmes d'oppression opérant à partir de ces catégories et postule leur interaction dans la production et la reproduction des inégalités sociales". 
A adição de marcadores sociais como raça e classe ${ }^{12}$ reposicionam a categoria gênero e apontam como mulheres são impactadas de formas e graus diferentes quanto a qualidade e estilo de vida ou status social (Hooks, 1984; Biroli e Miguel, 2015). Neste sentido, a subordinação interseccional estrutural representa "uma gama complexa de circunstâncias em que as políticas se intersectam com as estruturas básicas de desigualdade" (Crenshaw, 2002, p. 179). Ou seja, os sistemas de dominação são múltiplos e não atingem os indivíduos isoladamente; é como uma interseção em uma via de trânsito na qual racismo, sexismo e classe social conjuntamente restringem ou potencializam as trajetórias das pessoas e constituem instituições, políticas e teorias que as afetam (Crenshaw, 2002; Biroli e Miguel, 2015).

Raça, classe e gênero surgem, assim, como categorias de análise paralelas e imbricadas que estruturam todas as relações e podem ajudar a entender as bases da dominação (Collins, 2015). Com essa categorização, é possível alterar a visão descritiva e normativa da sociedade que reforça o staus quo, examinando as complexidades de baixo para cima e colocando os que estão mais marginalizados no centro (Crenshaw, 1989). Se, para mulheres brancas, de classe média, a categoria gênero assume a primazia nas suas vidas, as mulheres negras, trabalhadoras mal remuneradas, frustradas com as burocracias das políticas de bem-estar social, experimentam os efeitos negativos das opressões de gênero, raça e classe simultaneamente (Collins, 2015).

Ocorre que, apesar da vulnerabilidade das mulheres estar ligada a estruturas comuns de dominação de gênero, existem outras formas de vulnerabilidade que impedem uma compreensão direta e universal da experiência de ser mulher ou de articular os interesses das mulheres como um grupo homogêneo. Por isso, ao evitar leituras universalizantes, o feminismo interseccional suscita a articulação entre as categorias de gênero, raça e classe para tentar superar desigualdades e entraves à liberdade.

Pesquisas com diferentes perspectivas teóricas e metodológicas são projetos de conhecimento que não podem estar desconectados das vivências de pessoas e dos processos de dominação específicos que impactam diversamente os indivíduos situados no espaço social. Assim, a interseccionalidade é um ponto de partida que pode ser inserido nos trabalhos acadêmicos e nas políticas que estão sendo realizadas, suscitando o que pode ser mobilizado para transformar a estrutura social que tenha múltiplas e conjugadas formas de opressão (Carbado, Crenshaw e Mays, 2013; Biroli e Miguel, 2015).

Mais especificamente, a construção de uma agenda acadêmica feminista a partir da interseccionalidade aponta um compromisso teórico-metodológico que pode contribuir para a discussão sobre a renda básica incondicional, haja vista que auxilia na

12 Neste trabalho, "não suspendemos a importância de outras variáveis, mas entendemos que as assimetrias que se definem no entrecruzamento e constituição recíproca desses três eixos são incontornáveis para a análise das desigualdades nas sociedades contemporâneas (Biroli e Miguel, 2015, p. 29)". 
análise das situações concretas das mulheres, bem como no exame da discriminação estrutural baseada não apenas no gênero — mas também nas discriminações múltiplas que contribuem para tornar algumas mulheres mais vulneráveis à pobreza e a várias privações de liberdade (Hirata, 2014; Rodrigues, 2015; Schulz, 2017).

Nesse contexto de renda básica, na Grã-Bretanha, em 1977, uma resolução que exigia uma "renda mínima garantida" foi aprovada na Conferência Nacional de Libertação da Mulher - estimulado em grande parte pelas mulheres da classe trabalhadora (Yamamori, 2014). Ocorre que, apesar de essa espécie de renda básica incondicional ser vista como uma maneira fundamental de reduzir a dependência dentro das famílias patriarcais, a proposta não foi levada adiante devido à oposição no movimento. Especificamente, de um lado, houve uma divisão entre as mulheres da classe média que não viram o benefício de uma renda garantida e, de outro, as mulheres da classe trabalhadora para as quais a questão era mais pertinente (Yamamori, 2014).

Esse exemplo é marcante de como o movimento feminista, em geral, é representativo dos interesses das mulheres brancas e de classe média — que exclui uma ampla gama de experiências feministas (Zack, 2007). Não raramente, membros de grupos sociais subordinados acomodam-se em subconjuntos, como nos casos de mulheres que se opõem à discriminação sexista, mas exploram mulheres pobres e não educadas no serviço doméstico (Meyers, 2000).

E, quando se trata de mulheres negras, as experiências tendem a não se representar nem nos discursos do feminismo, nem do antirracismo (Crenshaw, 1995). Por isso, o gênero não pode ser retratado como mais fundamental ou mais penetrante do que raça ou classe, nem pode ser retratado como secundário para qualquer uma dessas outras categorias de grupo. Na medida em que a identidade é moldada por essas estruturas sociais, há um misto de determinantes de identidade igualmente robustos e igualmente decisivos (Meyers, 2000).

Quando o gênero se intersecta com uma gama de outras identidades, as interações das discriminações contribuem para a vulnerabilidade particular de diferentes grupos de mulheres, por isso a ampliação de mecanismos de proteção, promoção de igualdade e liberdade deve dar atenção a experiências específicas de mulheres que tenham vulnerabilidades interseccionais ofuscadas ou marginalizadas (Crenshaw, 2002). A interseccionalidade trata, assim, da forma como ações e políticas específicas geram opressões que fluem ao longo dos eixos do gênero, da raça e da classe, constituindo aspectos dinâmicos ou ativos do "desempoderamento", de modo que o problema não está apenas na desconsideração das vulnerabilidades: o problema está na limitação das oportunidades de emprego e educação, por exemplo (Crenshaw, 2002).

No mercado de trabalho, algumas ocupações não estão disponíveis para candidatas com perfil étnico-racial e de gênero. Mulheres racializadas podem se confrontar 
com a discriminação composta, pela qual um grupo de mulheres são contratadas para funções que "envolvem interação com o público, enquanto as minorias raciais sejam empregadas no trabalho industrial ou em alguma outra forma de trabalho segregado" (Crenshaw, 2002, p. 179). Também na "educação as mulheres de determinada identidade étnico-racial podem ser excluídas das oportunidades educacionais ou ter menos anos de estudo em relação [...] às mulheres da elite" (Crenshaw, 2002, p. 179).

As múltiplas opressões podem ser encontradas, também, em dados empíricos. No Brasil, por exemplo, de acordo com a análise feita pelo Instituto de Pesquisa Econômica Aplicada (Ipea) dos dados da Pesquisa Nacional por Amostra de Domicílios de 2014, do Instituto Brasileiro de Geografia e Estatística, os homens continuam ganhando mais do que as mulheres (em média, R\$1.831, contra R\$1.288, em 2014), e os homens brancos ganham ainda mais (R\$2.393, em 2014), enquanto as mulheres negras seguem na base, com renda de R\$946 no mesmo ano, ou seja, a pesquisa aponta a posição de desvantagem de mulheres negras (Ipea, 2016).

Os dados do Ipea (2014) também apontam que 57,8 \% dos homens e 59,1\% das mulheres se encontravam, em 2013, na faixa da população em situação de extrema pobreza, de pobreza e de vulnerabilidade (em todos os casos, com renda domiciliar inferior a um salário-mínimo). Ainda que essa diferença de 1,3 ponto percentual seja significativa, a distância entre as mulheres brancas e as mulheres negras é bem mais acentuada: entre as brancas, 45,9\% estão em condição de extrema pobreza, pobreza e vulnerabilidade; entre as negras, esse número chega a 70,9 \%. ${ }^{13}$ A convergência das variáveis apresentadas pode ser expressa pela seguinte figura:

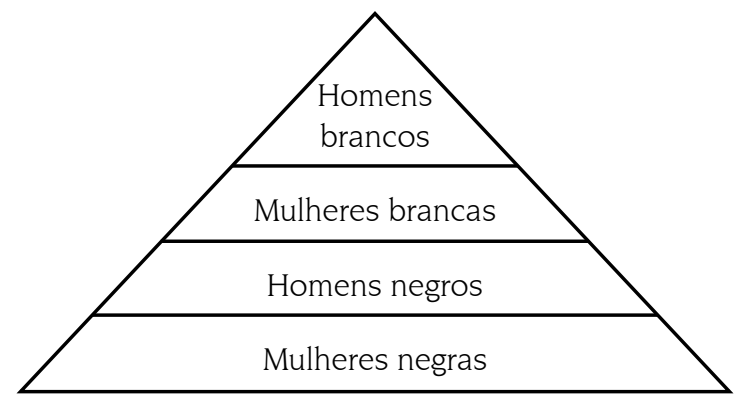

Figura 1. Pirâmide da convergência de múltiplas vulnerabilidades

Fonte: adaptado de Biroli e Miguel (2015, p. 41).

13 Esses números são baseados nos dados do Programa Brasil Sem Miséria que trabalha com as seguintes variáveis e valores para o ano de 2013: extremamente pobres são indivíduos com renda domiciliar per capita de até R\$79,12; pobres são aqueles com renda domiciliar per capita maior ou igual a $R \$ 79,12$ e menor que R\$158,24; vulneráveis têm renda domiciliar per capita maior ou igual a R\$158,24 e menor que R\$678, valor do salário mínimo em 2013. Para mais análises desses dados, ver Biroli e Miguel (2015). 
Nota-se, desse modo, que teorias e políticas se intersectam com as estruturas básicas de desigualdade, criando uma mescla de opressões para mulheres especialmente vulneráveis, podendo afetá-las de muitas formas. Por isso, quando as teorias não são, de alguma forma, direcionadas a indivíduos marginalizados, há um entrecruzamento com outras estruturas, agravando a subordinação (Crenshaw, 2002). Crenshaw dá o seguinte exemplo acerca da retração de serviços que antes eram fornecidos pelo Estado:

Quando o Estado corta recursos relativos aos cuidados com os jovens, doentes e idosos, as necessidades não supridas recaem, em grande parte, sobre os ombros das mulheres, a quem tradicionalmente se atribuíram essas responsabilidades. Além disso, as adicionais estruturas de classe determinam quais mulheres executarão fisicamente esse trabalho e quais mulheres pagarão outras, economicamente desfavorecidas, para que prestem esse serviço. Assim, mulheres pobres acabam tendo de carregar o peso do cuidado da família dos outros, além da própria. As consequências do ajuste estrutural [...] colocam tais mulheres em uma posição econômica que as força a assumir ainda mais trabalho, geralmente marcado pelo gênero, que as mulheres da elite podem assegurar através do mercado. (pp. 180-181)

Observa-se, portanto, que as consequências da subordinação interseccional não precisam ser intencionalmente produzidas por teorias ou pelas políticas, mas, ao desconsiderar as experiências de mulheres marginalizadas, surge um ônus - o risco de atingir não o topo, mas a base da pirâmide em que se situam profundas desigualdades complexas (Crenshaw, 2002). Por isso, é importante trazer o feminismo interseccional para o debate da renda básica incondicional que direciona recursos para as mulheres indiscriminadamente, uma vez que isso pode afetar as mulheres de diferentes maneiras (Fitzpatrick, 2013).

O feminismo interseccional permite analisar questões de justiça distributiva, de ação política e de poder, aproximando-se dos estudos focados em justiça (Hancock, 2007; Biroli e Miguel, 2015). Assim, se a interação entre as discriminações de raça e de classe não ficam obscurecidas dentro de categorias mais amplas, como o gênero, aumenta-se a possibilidade de que mais mulheres sejam beneficiadas pela ampliação de igualdade e de liberdade.

Ao lançar mão da noção de interseccionalidade, incorporando gênero, raça e classe, pode-se reforçar os fortes argumentos baseados na igualdade, na liberdade e na justiça em defesa da renda básica (Schulz, 2017). Até porque o "entrelaçamento complexo [...] faz com que qualquer interpretação aprofundada do mundo social e qualquer projeto emancipatório consequente precise incorporar simultaneamente os três eixos" (Biroli e Miguel, 2015, p. 28). Há, inclusive "um interesse jurídico em articular sexo e raça" (Hirata, 2014, p. 64).

Portanto, diante das profundas desigualdades raciais, de classe e de gênero, a interseccionalidade surge para consolidar teorias mais apropriadas a essa realidade, desafiando o modelo hegemônico de mulher universal (Rodrigues, 2013; Magliano, 
2015). O feminismo interseccional serve para recuperar "as preocupações sobre as consequências sociais e materiais das categorias gênero, raça e classe" e, assim, "desconstruir certas categorias, desmascarar os falsos universalismos e identificar a dinâmica de poder predominante" (Magliano, 2015, p. 695). ${ }^{14}$

Além do aspecto acadêmico e político, a interseccionalidade surge como possibilidade de mudança social e para alterarmos nossas relações uns com os outros. Há falhas políticas, acadêmicas e nas ações do cotidiano que mantêm a subordinação de outras pessoas, por isso, é preciso reexaminar nossas posições (Collins, 2015). No contexto da política renda básica incondicional, o feminismo interseccional abre um relevante espaço para a análise de desigualdades sociais específicas, promovendo uma compreensão mais dinâmica das experiências vivenciadas por vários grupos de mulheres, como veremos na próxima seção.

\section{RENDA BÁSICA À LUZ DO FEMINISMO INTERSECCIONAL}

Van Parijs e Vanderborght (2017) afirmam que em "praticamente qualquer reforma imaginável de renda básica, as mulheres se beneficiariam muito mais do que os homens, seja em termos de renda ou em termos de opções de vida" (Van Parijs e Vanderborght, 2017, p. 185). ${ }^{15}$ Analisaremos essa afirmação sob a perspectiva do feminismo interseccional nestes dois aspectos indicados: opções de vida e renda.

A análise dos possíveis benefícios da renda básica incondicional para mulheres em termos de "opções de vida" será feita em duas frentes. A primeira frente trata dos efeitos da "neutralidade e da universalidade" da renda básica. A segunda frente trata da capacidade da renda básica de superar a própria diversidade dominada concebida por Van Parijs.

Por um lado, a renda básica apresenta-se como base material firme para cada um desenvolver sua própria concepção de vida boa, o que poderia favorecer a superação do modelo do breadwinner' ${ }^{16}$ ara a criação de uma noção de neutralidade de gênero (Robeyns, 2013). Neutralidade de gênero, nesse sentido, quer dizer incluir as mulheres como membros plenos da sociedade, ou seja, o papel da renda básica seria corrigir a expectativa de papéis de gênero que conduzem mulheres a trabalhos gratuitos de cuidado do lar e geração de filhos, trabalhos estes relegados a posições marginais

14 [No original] "Dicha perspectiva recupera las preocupaciones em torno a las consecuencias sociales y materiales de las categorías género, etnicidad, raza y clase [...] la necesidad de deconstrucción de ciertas categorías, de desenmascarar los falsos universalismos y de identificar las dinámicas de poder imperantes".

15 [No original] "Under practically any imaginable basic-income reform, women would benefit far more than men, whether in terms of income or in terms of life options".

16 "Embora agora seja comum (mesmo não incontestado) entender a 'família' como abrangendo uma gama de possíveis relacionamentos pessoais, a maioria dos sistemas do estado de bem-estar se baseava em uma forma particular de família - o núcleo familiar baseado no breadwinner masculino e na dona-de-casa feminina" (McKay e Vanevery, 2000, p. 274) 
(Robeyns, 2013). A política de renda básica, assim, poderia corrigir a atribuição desproporcional de responsabilidades domésticas e dar às mulheres maiores condições de igualdade de competição por trabalhos assalariados (Zelleke, 2008). Ou seja, poderia permitir à mulher ter possibilidades de escolhas reais, para além da responsabilidade que hoje a ela é atribuída a priori (Robeyns, 2000; Robeyns, 2013).

Nesses aspectos, a renda básica incondicional aparenta ter vantagens em relação a outras políticas: a perspectiva de universalismo e neutralidade. $O$ fato de conceder recursos a todas as pessoas, indiscriminadamente, permite que ninguém tenha que ser especializado entre trabalho assalariado ou trabalho de cuidado, de modo que caberá à autonomia do indivíduo escolher como se dariam seus papéis nos mais distintos contextos. A renda básica, assim, forneceria renda e alguma segurança econômica para todos, sendo neutra a respeito das escolhas das pessoas e permitindo, em tese, o exercício de liberdade de opções de vida (McLean, 2015).

De forma geral, esse posicionamento já é passível de críticas. A crítica mais forte é que, na busca por uma mudança na divisão de gênero do trabalho remunerado e não remunerado, a implementação de uma renda básica, teoricamente, é neutra em termos de gênero, de modo que pais e mães teriam o mesmo incentivo. Na prática, sobretudo nos casos de baixo valor de renda básica, a consequência (não intencional) seria de encorajar um retorno ao modelo breadwinner, com um dos pais mais apto a ficar em casa, mas o outro ainda teria necessidade de permanecer firmemente ligado ao mercado de trabalho (Koslowski e Duvander, 2018).

Zelleke (2008) resume outros possíveis problemas em relação à pauta da neutralidade de gênero: $O$ primeiro é que institucionalizar a neutralidade de gênero, após gerações de privilégios exclusivos, pode ocasionar efeitos discriminatórios no mercado e na sociedade. O segundo é que não há garantias de que os papéis de gênero seriam modificados na vida familiar. O terceiro problema é que não há garantias de que o nível salarial seria equiparado entre homens e mulheres no mercado e, por fim, a neutralidade de gênero ainda precisa amadurecer para tratar de distinções fisiológicas, como a gravidez, tratada em muitos contextos como "incapacidade temporária" exclusiva da mulher.

De forma específica, sob a vertente do feminismo interseccional, as críticas são de outra natureza. A renda básica, em tese, pode cumprir todos os requisitos de provimento de liberdade real para mulheres brancas e de classe média, tipicamente dentro de padrões de países desenvolvidos, mas não pode deixar de considerar questões contingenciais que variam conforme cada realidade social ou cultural (Coelho, 2018). Como apresentamos na segunda seção, há múltiplas realidades da experiência feminina em que, na interseção de gênero, raça e classe, são aumentados os riscos de pobreza, de violência doméstica e de controle autoritário sobre a vida de muitas mulheres (McLean, 2015). A questão que surge é: para essas mulheres, a renda básica 
incondicional consegue trazer mais opções de vida? Em que medida experiências específicas de mulheres são abarcadas por uma política universalizante e dotada de neutralidade, como a de Van Parijs?

"Desuniversalizar" o conceito de mulher quando outras relações de poder estão atravessadas é o primeiro passo para responder essas perguntas, porque as identidades sociais fazem diferença na maneira como mulheres vivenciam a discriminação (Crenshaw, 2002; Curiel, 2018). As opressões de gênero, raça e classe formam o pano de fundo estrutural em que as relações são enquadradas, gerando desigualdade e exploração para mulheres excluídas do feminismo hegemônico. As experiências moldadas por outros sistemas de estratificação social além do gênero, acrescentam facetas na identidade que influenciam nos desejos e atitudes (Zack, 2007).

Nesse sentido, as intersecções de gênero, raça e classe levam pessoas a julgar mal o seu potencial, a perseguir planos que impedem seu desenvolvimento ou suas capacidades, de modo que a influência inconsciente sabota seus interesses e prejudica a propriedade de si mesmo (Meyers, 2000). Se estamos lidando com opções de vida, e a liberdade real de Van Parijs utiliza como métrica o respeito por escolhas e desejos, as questões de identidade interseccional são especialmente importantes, porque influenciam na formação das concepções de bem dessas mulheres.

Muitos fatores convergem para a formação dos desejos. As origens das perspectivas morais gerais de uma pessoa - e de suas preferências específicas — são alimentadas pelo contexto social e pela identidade interseccional (Meyers, 2000). As identidades influenciam no que as pessoas acreditam, como deliberam e como conduzem suas vidas. Os objetivos e os planos pessoais derivam do modo como os indivíduos internalizam gênero, raça e classe. As categorias de acordo com essas múltiplas abordagens interagem e - às vezes - combinam os efeitos, criando divisões internas e conflitos, alterando a visão sobre quem são, como pensam, como agem (Meyers, 2000). Nos termos de Van Parijs, é a criação da "escrava satisfeita".

A forma como os desejos e preferências são formados podem ser obstáculos às opções de vida se as pessoas nascem e se socializam para aceitar e talvez se identificar com situações de subordinação e servilismo altamente limitadas (Pettit, 1997). Nessa perspectiva, as diferenças advindas de marcadores sociais como raça e classe não devem ser ignoradas, porque podem implicar desvantagens na formação do "desejo potencial" de algumas mulheres. Assim, o ponto de vista universalizante e neutro da renda básica esvazia as particularidades das mulheres, comprometendo a heterogeneidade das experiências, as quais desconsideradas podem causar o efeito oposto ao desejado da renda básica incondicional, ou seja, menos liberdade de escolha.

A suposta neutralidade e universalidade da renda básica não é experimentada da mesma forma por todos os indivíduos, sobretudo as mulheres que passam por 
discriminações múltiplas, as quais devem ser levadas em conta ao desenvolver uma teoria (Hankivsky e Cormier, 2011). Do ponto de vista da interseccionalidade, a renda básica pode ser tão ineficaz quanto outras teorias e políticas que falham em abordar múltiplas identidades e diversidades (Hankivsky e Cormier, 2011).

É importante pontuar que gênero, raça e classe se entrelaçam para estruturar as dimensões institucional, simbólica e individual nas quais a opressão é estruturada (Harding, 1987). Entretanto, nem todas as mulheres são afetadas igualmente pelo mesmo entrelaçamento simbólico. Cada uma tem uma biografia individual moldada à sua maneira, ou seja, cada uma carrega o efeito acumulativo das experiências vividas nas estruturas de opressão. Isso quer dizer que os indivíduos não estão condenados a seguir os caminhos trilhados pela raça, classe ou gênero (Crenshaw, 2002; Collins, 2015).

Van Parijs, assim como outros teóricos políticos contemporâneos, não pressupõe inferioridade natural da mulher e as aceitam inclusas no domínio público com acesso igual à educação, emprego e cargos públicos. Só que os efeitos da igualdade e da liberdade não foram suficientemente atingidos pelas mulheres (Kymlicka, 2006; Zirbel, 2016). Ao pautar a liberdade real por uma ideia de igualdade e liberdade uniformizante e androcêntrica - tanto em seus aspectos descritivos, quanto normativos - desconsiderando condições materiais e sociais produzidas pelo sistema de gênero, raça e classe, cria-se um obstáculo que impede as mulheres de fazer o que poderiam querer fazer. Por isso, a proposta de renda básica pode ser insuficiente para fazer avançar as demandas do feminismo interseccional, uma vez que não parece atender demandas de superação das estruturas de desigualdades para variados grupos de mulheres.

Questiona-se, outrossim, a capacidade da renda básica em superar a própria diversidade dominada concebida por Van Parijs, quando pensada em discriminação de gênero (Birnbaum, 2004). Essa será a segunda frente da análise da afirmação de Van Parijs e Vanderborght (2017) quanto aos benefícios da política de renda básica para mulheres, em termos de opções de vida. Essa crítica é especialmente pertinente nos casos de discriminação transversal que adiciona outros indicadores como raça e classe.

Como vimos na primeira seção desta pesquisa, Van Parijs (1995) defende um critério unânime para compensar a sorte. Essa compensação seria feita antes de distribuir uma renda básica incondicional para todos. Na compensação pelas desigualdades, Van Parijs (1995) usa o conceito de "diversidade dominada" como um critério para compensar a sorte bruta. ${ }^{17}$ Segundo o autor, primeiro, o azar bruto deve ser compensado e depois, com os recursos restantes, uma renda básica deve ser distribuída. Nesse caso, é necessário que todos considerem que os recursos internos e externos

17 As teorias liberais contemporâneas da justiça têm discutido como o Estado poderia compensar a sorte. As diferentes teorias igualitárias liberais da justiça defenderam várias maneiras de fazer essa compensação, a partir da distinção entre a sorte de opção e a sorte bruta. A primeira é uma consequência das decisões que as pessoas tomam durante suas vidas e elas são responsáveis por elas. A segunda é devido ao mero acaso (Dworkin, 1981a; Dworkin, 1981b). 
dados sejam unanimemente preferidos ao que é dado a outro indivíduo. Se houver algum membro afastado da unanimidade, isso pode tornar a redistribuição impossível. Assim, a renda básica está condicionada à compensação da desigualdade de dotações por má sorte bruta.

Contudo, as pessoas são boas em coisas diferentes e existe uma ampla gama de convicções éticas razoáveis em relação ao que constitui as capacidades mais valiosas da vida. Em uma sociedade eticamente diversa, a maioria dos casos de desvantagem relativa pode, portanto, neutralizar-se mutuamente (Birnbaum, 2004). Geralmente, a dotação de uma pessoa não é unanimemente considerada mais favorável do que a de outra pessoa. A diversidade não-dominada é uma relação entre os cidadãos "A" e "B" que é percebida quando nenhum deles tem uma dotação abrangente (interna e externa, ou seja, recursos pessoais e impessoais) que todos os cidadãos da comunidade (dadas suas concepções de bem) ache menos favorável que o do outro. "Todos" e "unanimemente" devem ser tomados com algumas reservas, dadas as exigências de que as pessoas sejam sinceras, bem informadas, tenham uma compreensão suficiente das consequências de ter várias desvantagens, suas preferências acessíveis e compreensíveis para o resto da comunidade (Birnbaum, 2004).

Mas o que a diversidade dominada implica para o problema da discriminação de gênero, em um contexto interseccional? De acordo com Van Parijs:

Quanto mais discriminação étnica, sexual ou de outra natureza existe [...] mais provável é que a dotação interna de algumas pessoas seja dominada pela dos outros, e mais os recursos da sociedade terão, portanto, que ser direcionados para categorias específicas, em vez de serem usadas para maximizar a renda básica. ${ }^{18}$ (Van Parijs, 2001, p. 114)

Logo, a unanimidade dos acordos sobre o que é (des)vantajoso ao indivíduo no tocante à diversidade dominada é problemática, uma vez que as implicações de consenso dependerão muito de como a comunidade política em questão é demarcada. Quanto maior a diversidade nas concepções éticas, menor será o padrão mínimo social e cultural acordado, por isso é preciso ter o reconhecimento da relevância moral das dotações inferiorizadas (Birnbaum, 2004). Há muitos indivíduos que se adaptaram à sua subordinação e consideram suas expectativas mais baixas como um fato natural da vida. Se essas pessoas não se preocupam muito em ter oportunidades de carreira iguais ou acesso igual a outras esferas sociais importantes, nenhuma política para neutralizar essa exclusão fará efeito. Assim, a compensação da "diversidade dominada" opera apenas em um ambiente onde as convicções de inferioridade e superioridade já são amplamente aceitas (Birnbaum, 2004). Esse é o problema.

18 [No original] "The more ethnic, sexual, or other discrimination there is [...] the more likely it is that some people's internal endowment will be dominated by that of others, and the more of society's resources will therefore need to be targeted to specific categories, rather than used to maximize UBI [basic incomel". 
A dimensão interseccional das desigualdades de gênero leva a validade da renda básica incondicional a uma encruzilhada. A relevância moral das medidas redistributivas depende de atitudes subjetivas reais contra a discriminação. Em outras palavras, apenas redistribuir recursos não seria suficiente se, em uma instância subjetiva, discriminações pautadas em raça e classe perduram (Birnbaum, 2004). De um lado, existem pessoas que estão tão acostumadas a ter um padrão baixo de vida, que suas baixas expectativas são dadas como fato natural. Por outro lado, a verdadeira mudança capaz de reduzir ou mesmo anular essas discriminações seriam de cunho subjetivo. Nesse sentido: (1) precisa ser importante para todos os indivíduos que todos tenham amplas oportunidades; (2) precisa ser importante para todos os indivíduos que não haja discriminação de qualquer natureza entre as pessoas; (3) precisa ser importante para todas as pessoas que haja um padrão de igualdade nas relações sociais. De outra forma, não há superação da desigualdade (Birnbaum, 2004).

Portanto, apenas a renda básica, mesmo com a condicionante da diversidade não dominada, parece não dar conta de resolver a questão das diversidades, em contextos outros que não aqueles caracterizados pela propriedade de si mesmo. Por uma perspectiva interseccional, há validade instrumental na redistribuição de recursos, mas não há validade substantiva. A redistribuição de recursos por meio de uma política de renda básica incondicional contribui para mudanças em contextos de discriminação, mas tal contribuição é acessória. Logo, é apenas um fator auxiliador para uma mudança mais ampla necessária que reside na dimensão social subjetiva.

Dando sequência às análises da afirmação de Van Parijs e Vanderborght (2017) quanto aos benefícios da renda básica para mulheres, concentemos agora no aspecto da "renda". Como dito, há uma crescente demanda de análises que busquem compreender a capacidade da renda básica de suprir demandas feministas interseccionais, com vistas à superação de modos de opressão, atentas a questões de origem histórica, cultural e política que causam grandes discriminações não apenas de homens em relação a mulheres, mas também de mulheres em relação às próprias mulheres (McLean, 2015; Coelho, 2018).

Para Robeyns (2000; 2013), a renda básica possibilita às mulheres aumento do leque de opções de vida, para além das escolhas imposta por papéis sociais de gênero. Desse modo, seria uma forma de melhorar as condições de vida para os grupos mais vulneráveis, como mães-solo, por exemplo. Essas mães, que antes se viam constrangidas a trabalhar em jornadas duplas ou triplas (trabalho de cuidado, trabalho assalariado e estudos), poderiam escolher se especializar nas ocupações que melhor lhes aprouver.

Entretanto, é controverso se a renda básica teria a capacidade de minorar diferenças de raça e classe entre grupos de mulheres, visto que os recursos seriam 
direcionados na mesma medida tanto a mulheres que possuem uma carreira consolidada, quanto àquelas que não possuem oportunidade de desenvolver uma carreira no mercado (Fitzpatrick, 2013). Segundo Fitzpatrick (2013), os questionamentos referentes a esse ponto dizem respeito à possibilidade de grupos mais vulneráveis de mulheres que já estão fora do mercado, uma vez sendo fortalecidos pela renda básica, sejam forçosamente reconduzidos às atividades domésticas, diferentemente de mulheres brancas de classe média ou alta que tiveram acesso a oportunidades de estudo e trabalho, o que não faria mais do que acentuar os preconceitos e discriminações já existentes em relação ao primeiro grupo.

Essa crítica mostra-se consistente, sobretudo nos contextos em que o valor da renda básica é baixo, pois explicitam as diferenças que emergem entre as mulheres no que se refere à raça e à classe. Brenner (2000) argumenta que a vantagem econômica das mulheres de classe média e alta acabaria levando à exploração das mulheres da classe trabalhadora. Alguns estudos mostram que as mulheres de carreira de classe média e alta tendem a contratar mulheres da classe trabalhadora (por exemplo, faxineiras e babás) e pagam para fazerem trabalhos domésticos e cuidar de crianças, para que elas (as mulheres de carreira) possam evitar trabalho extra em casa (Brenner, 2000). Essas mulheres de carreira tentam manter o salário das mulheres da classe trabalhadora o mais baixo possível para que se obtenha o máximo possível da maisvalia resultante do trabalho das mulheres da classe trabalhadora.

Assim, ao conceder uma renda básica incondicional baixa, as estruturas ocupacionais mantêm-se divididas com base não apenas no gênero, mas na raça e na classe. Biroli e Miguel (2015, p. 42) explicam que, para mulheres "brancas e altamente escolarizadas, o acesso a carreiras em campos como a medicina, a engenharia e o direito de fato redefiniu sua posição", entretanto, no outro polo, estão "mulheres que são em sua maioria negras, jovens e pouco escolarizadas: são as que exercem trabalho doméstico remunerado" (Biroli e Miguel, 2015, p. 42).

Por essa razão, no debate feminista interseccional sobre renda básica, as interseções entre gênero, raça e classe são especialmente relevantes, porque podem ajudar a promover metas de igualdade no contexto de heterogeneidade entre as mulheres (McLean, 2016). Segundo McLean (2016, p. 288), como a desvantagem de gênero não captura a soma total da experiência feminina, a "interseccionalidade oferece uma oportunidade para ampliar o debate feminista sobre renda básica além do cuidado, e para melhor incorporar insights sobre a diversidade da experiência das mulheres"; ${ }^{19}$ desse modo, é possível fortalecer o argumento para uma renda básica em relação ao objetivo de liberdade e igualdade para todos os grupos de mulheres.

19 [No original] "Attention to intersectionality provides an opportunity to widen the feminist debate about basic income beyond care alone, and to better incorporate insights about the diversity of women's experience" 
Além disso, a proposição de renda básica de Van Parijs não faz conexão com noções de necessidades básicas, ou seja, o valor da renda básica pode ficar aquém do que é considerado "necessário para uma existência decente" (Van Parijs, 1994, p. 77). Por isso, é questionável se a política de renda básica incondicional é a estratégia mais promissora para desafiar os vários eixos de vulnerabilidades apresentados pela interseccionalidade. Talvez a renda básica, com valores que cubram ao menos a subsistência, seja um bom começo no caminho para a liberdade; contudo, pode não ser uma condição suficiente para desafiar as normas e as estruturas predominantes de gênero, raça e classe. A renda básica incondicional e universal, tomada como uma panaceia para todos os males, parece ser um equívoco. Embora possa ser um instrumento de liberdade necessário, o dinheiro sozinho não é, per si, suficiente para atender a integralidade dos desafios apresentados pelo feminismo interseccional.

\section{CONCLUSÕES}

Esta pesquisa propôs uma análise da política de renda básica incondicional de Philippe Van Parijs à luz do feminismo interseccional. Ao ampliar o debate sobre renda básica para mulheres que vivenciam entraves à liberdade e à igualdade advindos da interseção entre gênero, raça e classe, chegaram-se às seguintes conclusões.

Sob o ponto de vista das opções de vida, há algumas limitações na proposta de Van Parijs. O caráter universalizante e neutro da renda básica esvazia as particularidades das mulheres que passam por discriminações transversais e pode causar o efeito oposto ao desejado da renda básica incondicional, qual seja, menos liberdade de escolha. Ainda que a liberdade real de Van Parijs utilize como métrica o respeito por escolhas e desejos, a teoria desconsidera a manipulação de preferência dentro das estruturas de poder e a complexidade das identidades sociais - que influenciam os desejos potenciais e a formação da concepção de bem dessas mulheres. Por essas razões, essa proposta de renda básica pode ser insuficiente para fazer avançar as demandas do feminismo interseccional.

Além disso, a renda básica vanparijsiana, mesmo com a condicionante da diversidade não dominada, parece não dar conta de resolver a questão das diversidades, em contextos outros que não aqueles caracterizados pela propriedade de si mesmo. A redistribuição de recursos por meio da renda básica incondicional contribui para mudanças em contextos de discriminação, mas tal contribuição é acessória, pois requer uma mudança mais ampla que reside na dimensão social subjetiva. Desse modo, a relevância moral das medidas redistributivas depende de atitudes subjetivas reais contra a discriminação, o que aponta para a insuficiência da política de renda básica.

Sob o ponto de vista da renda, a análise apontou que a limitação na política de renda básica de Van Parijs é de cunho valorativo. Por um lado, a renda básica poderia ser uma forma de melhoria de condições de vida para os grupos mais vulneráveis, 
por outro, conceder uma renda básica incondicional de baixo valor manteria as estruturas ocupacionais divididas com base não apenas no gênero, mas na raça e na classe. Além disso, como não há conexão de renda básica incondicional com a noção de necessidades básicas, ou seja, o valor da renda básica pode ficar aquém do que é considerado necessário para sobrevivência, contestou-se a proposta do autor como a estratégia mais promissora para desafiar os vários eixos de vulnerabilidades apresentadas pelo feminismo interseccional.

Conclui-se, portanto, analisando as proposições vanparijsianas em termos de "opções e vida" e de "renda" das mulheres que sofrem desigualdades complexas, que a política de renda básica proposta por Van Parijs, embora possa ser um instrumento de liberdade necessário, não consegue atender a integralidade dos desafios apresentados pelo feminismo interseccional, o que refuta hipótese inicial deste trabalho.

\section{REFERÊNCIAS}

Ackerman, B. (1980). Social justice in the liberal state. Yale University Press.

Berlin, I. (1969). Four essays on liberty. Oxford University Press.

Bilge, S. (2009). Théorisations féministes de l'intersectionnalité. Diogène, 1(225), 70-88.

Birnbaum, S. (2004). Real-libertarianism, Structural injustice and the democratic ideal. BIENs 10th Congress, The Right to a Basic Income: Egalitarian Democracy, 1-32. https://basicincome.org/bien/ pdf/2004Birnbaum.pdf

Birnbaum, S. (2012). Basic income reconsidered: Social justice, liberalism, and the demands of equality. Palgrave Macmillan.

Biroli, F. e Miguel, L. F. (2015). Gênero, raça, classe: opressões cruzadas e convergências na reprodução das desigualdades. Mediações, 20(2), 27-55. http://dx.doi.org/10.5433/2176-6665.2015v20n2p27

Brasil (2004, 9 de janeiro).). Lei n. ${ }^{0}$ 10.836. Cria o Programa Bolsa Família e dá outras providências. http:// www.planalto.gov.br/ccivil_03/_Ato2004-2006/2004/Lei/L10.836.htm

Brasil (2020, 2 de abril). Lei n. ${ }^{\circ}$ 13.982. Estabelece medidas excepcionais de proteção social a serem adotadas durante o período de enfrentamento da emergência de saúde pública de importância internacional decorrente do coronavírus (Covid-19). http://www.planalto.gov.br/ccivil_03/_ato2019-2022/2020/lei/113982.htm

Brenner, J. (2000). Women and the politics of class. Monthly Review.

Buchanan, J. M. (1975). The limits of liberty: Between anarchy and Leviathan. University of Chicago Press.

Carbado, D., Crenshaw, K. e Mays, V. M. (2013). Intersectionality: Mapping the movements of a theory. Du Bois review: Social science research on race, 10(2), 303-312. https://doi.org/10.1017/S1742058X13000349

Coêlho, D. B. (2012). Brazil: Basic income - A new model of innovation diffusion. Em M. Matthew e C. Pateman, Basic income worldwide. Horizons of reform (pp. 59-80). Palgrave Macmillan.

Coelho, L. (2018). Rendimento Básico Incondicional, Segurança Económica e Igualdade de Género, no Quadro do Capitalismo Pós-industrial. Revista Portuguesa de Filosofia, 74(2-3), 729-758. https:// www.jstor.org/stable/26510000 
Collins, P. H. (2015). Em direção a uma nova visão: raça, classe e gênero como categorias de análise e conexão. Em R. Moreno, Reflexões e práticas de transformação feminista (pp. 43-74). SOF — Sempreviva Organização Feminista. http://www.sof.org.br/wp-content/uploads/2016/01/reflex\%C3\%B5esepra ticasdetransforma\%C3\%A7\%C3\%A3ofeminista.pdf

Crenshaw, K. (1989). Demarginalizing the intersection of race and sex: A black feminist critique of antidiscrimination doctrine, feminist theory and antiracist politics. University of Chicago Legal Forum (1), 139-167. https://chicagounbound.uchicago.edu/uclf/vol1989/iss 1/8

Crenshaw, K. (1995). Mapping the Margins: Intersectionality, Identity Politics, and Violence Against Women of Color. Em N. Kimberle Crenshaw (ed.), Critical race theory: The key writings (pp. 357-383). New Press.

Crenshaw, K. (2002). Documento para o encontro de especialistas em aspectos da discriminação racial relativos ao gênero. Revista Estudos Feministas, 10(1),171 188. https://dx.doi.org/10.1590/ S0104-026X2002000100011

Curiel, O. (2018). Género, raza, sexualidad: debates contemporáneos. http://www.urosario.edu.co/urosario_ files/1f/1f1d1951-0f7e-43ff-819f-dd05e5fed03c.pdf

Diniz, S. (2007). Critérios de justiça e programas de renda mínina. Revista Katálysis, 10(1), 105-114. https://doi.org/10.1590/S1414-49802007000100012

Dworkin, R. (1981a). What is equality? Equality of welfare. Philosophy \& Public Affairs, 10(3), 185-246.

Dworkin, R. (1981b). What is equality? Equality of resources. Philosophy \& Public Affairs, 10(4), 283-345.

Elster, J. (1983). Sour grapes: Studies in the subversion of rationality. Cambridge University Press.

Fitzpatrick, T. (2013). A basic income for feminists? Em K. Widerquist, J. A. Noguera, Y. Vanderborght e J. De Wispelaere, Basic income: An anthology of contemporary research (pp. 163-172). Wiley Blackwell.

Hancock, A.-M. (2007). Intersectionality as a normative and empirical paradigma. Politics E Gender, 2(3), 248-254. https://doi.org/10.1017/S1743923X07000062

Hankivsky, O. e Cormier, R. (2011). Intersectionality and public policy: Some lessons from existing models. Political Research Quarterly, 64(1), 217-229. https://doi.org/10.1177/1065912910376385

Harding, S. G. (1987). Feminism and methodology: Social science issues. Indiana University Press.

Hayek, F. A. (1960). The constitution of liberty. University of Chicago Press.

Hirata, H. (2014). Gênero, classe e raça: interseccionalidade e consubstancialidade das relações sociais. Tempo Social, 26(1), 61-73. https://www.revistas.usp.br/ts/article/view/84979

Hooks, B. (1984). Feminist theory: From margin to center. South End Press.

Hunyadi, M. e Mänz, M. (1998). Does "Real-Freedom-for-All" Really Justify Basic Income? Swiss Political Science Review, 4(1), 43-63. https://doi.org/10.1002/j.1662-6370.1998.tb00232.x

Instituto de Pesquisa Econômica Aplicada — Ipea (2014). Retratos das desigualdades de gênero e raça. http://www.ipea.gov.br/retrato/indicadores.html

Instituto de Pesquisa Econômica Aplicada - Ipea (2016). Nota Técnica $n^{0} 24$ - Mulheres e trabalho: breve análise do período 2004-2014. http://www.ipea.gov.br/portal/images/stories/PDFs/nota tecnica/160309_nt_24_mulher_trabalho_marco_2016.pdf 
Koslowski, A. e Duvander, A.-Z. (2018). Basic income: The potential for gendered empowerment? Social Inclusion, 6(4), 8-15. http://dx.doi.org/10.17645/si.v6i4.1487

Kymlicka, W. (2006). Filosofia Política Contemporânea. Martins Fontes.

Magliano, M. J. (2015). Interseccionalidad y migraciones: potencialidades y desafíos. Estudos Feministas, 23(3), 691-712. https://periodicos.ufsc.br/index.php/ref/article/view/41761

McKay, A. e Vanevery, J. (2000). Gender, family, and income maintenance: a feminist case for citizens basic income. Social Politics: International Studies in Gender, State E Society, 7(2), 266-284. https://doi. org/10.1093/sp/7.2.266

McLean, C. (2015). Beyond care: Expanding the feminist debate on universal basic income. Wise Research Centre (1), 1-12.

McLean, C. (2016). ... and justice for all? Basic income and the principles of gender equity. Juncture, 22(4), 284-288. https://doi.org/10.1111/j.2050-5876.2016.00875.x

Meyers, D. T. (2000). Intersections identity and the authentic self? Opposites Attract!. Em C. Mackenzie e N. Stoljar (eds.), Relational autonomy: Feminist perspectives on automony, agency, and the social self (pp. 151-180). Oxford University Press.

Pettit, P. (1997). Republicanism: A theory of freedom and government. Oxford University Press.

Rego, W. G. e Pinzani, A. (2013). Vozes do Bolsa Família: autonomia, dinheiro e cidadania. Editora Unesp.

Robeyns, I. (2000). Hush money or emancipation fee? A gender analysis of basic income. 121-136. https://www.academia.edu/621286/An_emancipation_fee_or_hush_money_The_advantages_and_ disadvantages_of_a_basic_income_for_womens_emancipation_and_well-being

Robeyns, I. (2013). A gender analysis of basic income. Em K. Widerquist, J. A. Noguera, Y. Vanderborght e J. De Wispelaere, Basic income: An anthology of contemporary research (pp. 153-162). Wiley Blackwell.

Rodrigues, C. (2013). Atualidade do conceito de interseccionalidade para a pesquisa e prática feminista no Brasil. Seminário Internacional Fazendo Gênero 10, 1-12. http://www.fg2013.wwc2017.eventos.dype. com.br/resources/anais/20/1384445922_ARQUIVO_CristianoRodrigues.pdf

Rodrigues, T. (2015). Concepções de violência e interseccionalidade: Análise em um Centro de Referência de Atendimento a Mulheres em situação de violência [dissertação de mestrado em Psicologia, Universidade Federal de Minas Gerais). Repositório institucional http://www.fafich.ufmg.br/pospsicologia/ egressos/dissertacoes-mestrado/dissertacoes-mestrado-defendidas-em-2015/

Schulz, P. (2017). Universal basic income in a feminist perspective and gender analysis. Global Social Policy, 17(1), 89-92. https://doi.org/10.1177/1468018116686503

Silveira, D. T. e Córdova, F. P. (2009). Unidade 2 - A Pesquisa científica. Em T. E. Gerhardt, ee D. Tolfo, Métodos de pesquisa. Ed. da UFRGS.

Sommer, M. (2016). A feasible basic income scheme for Germany: Effects on labor supply, poverty, and income inequality. Springer. https://doi.org/10.1007/978-3-319-24064-0

Van Parijs, P. (1994). Capitalismo de renda básica. Lua Nova (2). http://dx.doi.org/10.1590/S0102 64451994000100005

Van Parijs, P. (1995). Real Freedom for All - What (if anything) can justify capitalism? Oxford: Oxford University Press. 
Van Parijs, P. (2001). Real freedom, the market and the family: A reply to seven critics. Analyse e Kritik, 23(1), 106-131. https://doi.org/10.1515/auk-2001-0109

Van Parijs, P. e Vanderborght, Y. (2017). Basic income: A radical proposal for a free society. Harvard University Press.

Vanderborght, Y. e Van Parijs, P. (2006). Renda básica de cidadania, argumentos éticos e econômicos. Civilização Brasileira.

Yamamori, T. (2014). A feminist way to unconditional basic income: Claimants unions and women's liberation movements in 1970s Britain. Basic Income Studies, 9(1), 1-24. https://doi.org/10.1515/ bis-2014-0019

White, S. (1997). Liberal equality, exploitation, and the case for an unconditional basic income. Political studies, 45(2), 312-326. https://doi.org/10.1111/1467-9248.00083

Zack, N. (2007). Can third wave feminism be inclusive? Intersectionality, its problems and new directions. Em M. A. Linda e K. E. Feder, The Blackwell Guide to Feminist Philosophy (pp. 193-207). Blackwell Publishing.

Zelleke, A. (2008). Should feminists endorse a basic income?: Institutionalizing the universal caregiver through an unconditional basic income. 12th BIEN Congress, 1-10. https://www.socialjustice.ie/sites/ default/files/file/BIEN/1 civzellekefbi.pdf

Zirbel, I. (2016). Reflexões feministas sobre a igualdade. Perspectiva filosófica, 41(1), 39-55. https:// periodicos.ufpe.br/revistas/perspectivafilosofica/article/view/230293 